\title{
2-Azanorbornane-based amine organocatalyst for enantioselective aldol reaction of isatins with ketones
}

\author{
Ayumi Ogasawara, ${ }^{a}$ U. V. Subba Reddy, ${ }^{a}$ Chigusa Seki, ${ }^{a}$ Yuko Okuyama, ${ }^{b}$ Koji Uwai, ${ }^{a}$ Michio \\ Tokiwa, ${ }^{\mathrm{c}}$ Mitsuhiro Takeshita, ${ }^{\mathrm{c}}$ and Hiroto Nakano ${ }^{\mathrm{a}, *}$ \\ ${ }^{a}$ Division of Sustainable and Environmental Engineering, Graduate School of Engineering, \\ Muroran Institute of Technology, 27-1 Mizumoto, Muroran 050-8585, Japan \\ ${ }^{b}$ Tohoku Medical and Pharmaceutical University, 4-4-1 Komatsushima, Aoba-ku, Sendai \\ 981-8558, Japan \\ ${ }^{c}$ Tokiwakai Group, 62 Numajiri Tsuduri-chou Uchigo Iwaki 973-8053, Japan \\ *Corresponding author. Tel.: +81 143465727. \\ E-mail address: catanaka@mmm.muroran-it.ac.jp (H. Nakano).
}

\begin{abstract}
Optically active 2-azanorbornane-based organocatalysts were designed and synthesized, and the catalytic activity of these catalysts in enantioselective aldol reactions of isatins with ketones was investigated. Among these catalysts, 2-azanorbornylmethanol showed the best catalytic activity to afford the corresponding aldol product in excellent chemical yield (up to 95\%) and with moderate stereoselectivity (up to $64 \%$ ee, up to syn:anti $=36: 64$ ).
\end{abstract}

\section{Introduction}

The development of new optically active organocatalysts for their use in asymmetric synthesis has attracted considerable interest in the scientific community over the past 10 years. Excellent covalent and non-covalent organocatalysts have been developed in a wide range of reactions. ${ }^{1}$ In recent years, we have developed various $\beta$-amino alcohols, which were utilized effectively as organocatalysts in different enantioselective reactions. ${ }^{2}$ 2-Azanorbornane $\mathbf{1}$ with a cage type structure, could be synthesized from the Diels-Alder reaction of cyclopentadiene with chiral iminodienophiles, which could find use as excellent synthetic intermediates, for deriving various biologically active compounds. ${ }^{3}$ 2-Azanorbornane-based cage compound $\mathbf{A}$, with a 
bulky 2-azanorbornane backbone and an amino nitrogen atom in the cage structure for the formation of an enamine moiety as a covalent site, could be synthesized from compound $\mathbf{1}$ (Scheme 1). Furthermore, compound $\mathbf{A}$ has the side chain at the 3-position on the 2-azanorbornane backbone, which can show strong electronic and steric effects through the formation of a hydrogen bond with the substrate and through steric control for the stereoselective reaction course. Considering these structural characteristics, it is expected that this cage type compound A might show an efficient functionality as an organocatalyst. However, only a few studies of the asymmetric reactions using compound $\mathbf{A}$ as an organocatalyst have

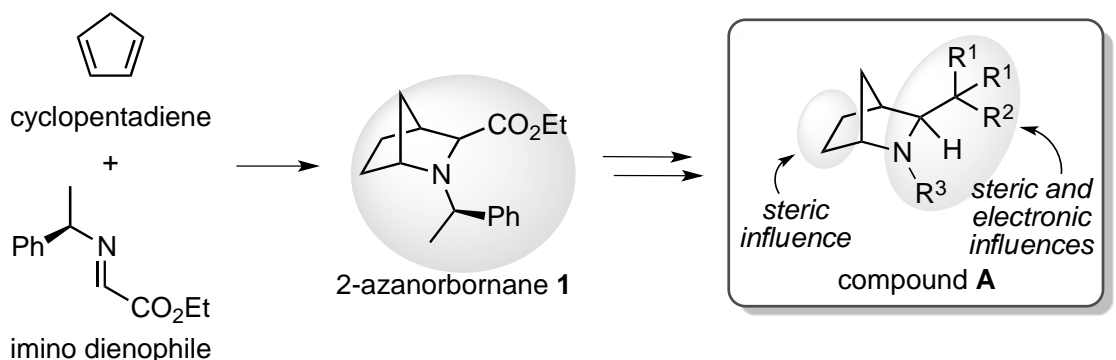

Scheme 1. Functional of 2-azanorbornanes.

been reported. ${ }^{3 b, c}$ Furthermore, to the best of our knowledge, the use of an organocatalyst with a cage structure such as 2-azanorbornane has never been reported in aldol reactions except for the use of a cinchonidine-thiourea type catalyst. ${ }^{3}$ For these reasons, we decided to explore the catalytic efficiency of 2-azanorbornane-based organocatalysts $\mathbf{B}$ in the aldol reaction of isatins with acyclic or cyclic ketones. ${ }^{4}$ The aldol reaction of isatins with acyclic or cyclic ketones is a versatile reaction for affording chiral 3-hydroxyl-2-oxindoles containing a stereogenic quaternary carbon center at the 3-position, which are useful intermediates for the synthesis of various biologically active compounds and pharmaceuticals. ${ }^{5}$ We hypothesized that the designed organocatalyst $\mathbf{B}$ having steric and electric control elements on both the 2-azabicyclo[2.2.1] octane backbone and at the side chain, could effectively control the stereoselective reaction course in the transition state $\mathbf{X}$ of this reaction (Scheme 2). Thus, the enamine intermediate, which is formed from the condensation of catalyst $\mathbf{B}$ with acyclic or cyclic ketones, could be fixed by both the hydrogen bonding of the nitrogen atom in the enamine part with the hydrogen atom of hydroxyl group on the side chain, and the two sterically bulky phenyl groups on the side chain. The enamine moiety might selectively attack the isatins to afford the corresponding aldol product in good chemical yield and stereoselectivity (Scheme 2). 


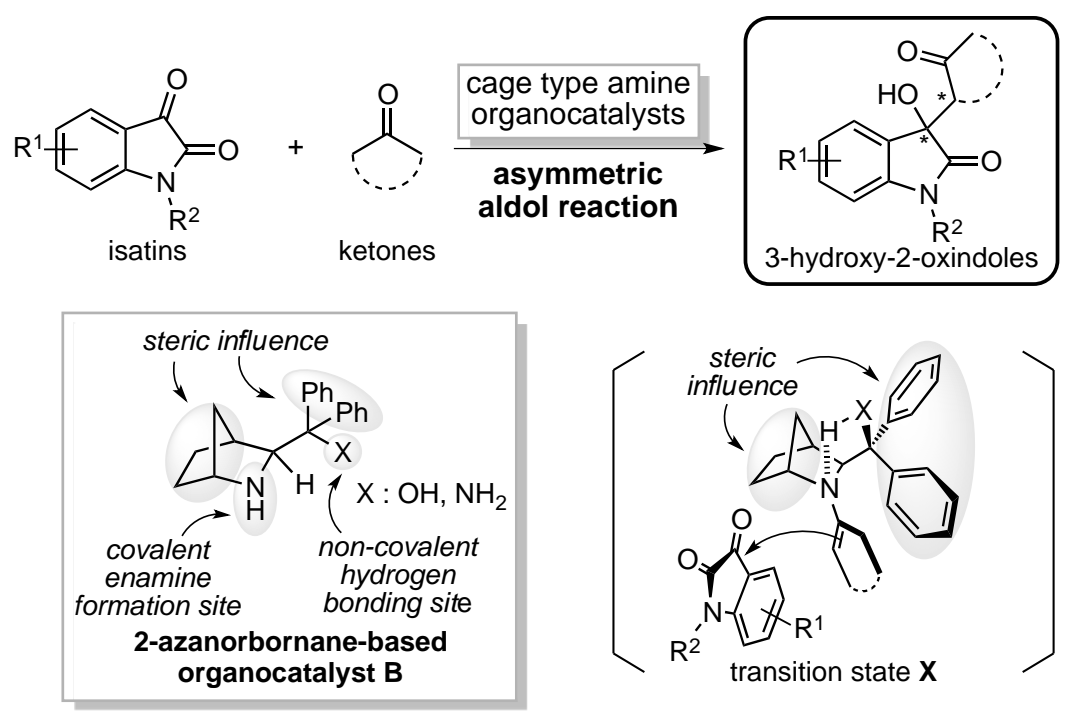

Scheme 2. Concept of catalyst design.

Herein we report that the prepared 2-azanorbornane-based organocatalysts showed asymmetric catalytic activity in the aldol reactions of isatins with acyclic or cyclic ketones to afford the corresponding aldol products in excellent chemical yield (up to 95\%) and with moderate stereoselectivity (up to $64 \%$ ee, up to syn:anti $=36: 64$ ).

\section{Results and Discussion}

Cage type amine organocatalysts 7, 8, 10, 11 and 15 with 2-azanorbornane or isoquinuclidine backbones were prepared as follows (Scheme 3). ${ }^{1,6}$ First, our previously reported 2-azanorbornylmethanol $\mathbf{5}$ with a diphenyl methanol moiety in the side chain was synthesized by the Diels-Alder reaction of cyclopentadiene with chiral imino dienophile 4, which was obtained by the condensation of aldehyde 2 with chiral amine 3 . The catalytic hydrogenation of Diels-Alder adduct 5 gave hydrogenated compound 1. The Grignard reaction of the obtained product 1 with phenyl magnesium bromide, followed by catalytic hydrogenolysis with palladium hydroxide afforded the desired compound $\mathbf{7}$ in good yield. 2-Azanorbornyltrimethylsilyldiphenylether 8 with a trimethylsilyl (TMS) protected hydroxyl group was obtained by the protection of $\mathbf{7}$ with TMSOTf in moderate yield. 2-Azanorbornyldiphenylamines $\mathbf{1 0}$ and $\mathbf{1 1}$ bearing a primary amino group in the side chain were prepared as a separable mixture from the reaction of $\mathbf{6}$ with $\mathrm{NaN}_{3}$, followed by catalytic hydrogenolysis of $\mathbf{9}$ with palladium hydroxide. Isoquinuclidine-based catalyst 15 with a 
2-azabicyclo[2.2.2] octane ring system was also synthesized via the same route as $\mathbf{7}$ using the Diels-Alder reaction of cyclohexadiene with 4 , catalytic hydrogenation of $\mathbf{1 2}$, Grignard reaction of $\mathbf{1 3}$ with phenyl magnesium bromide, followed by the catalytic hydrogenolysis of $\mathbf{1 4}$ with palladium hydroxide sequence in a moderate yield.
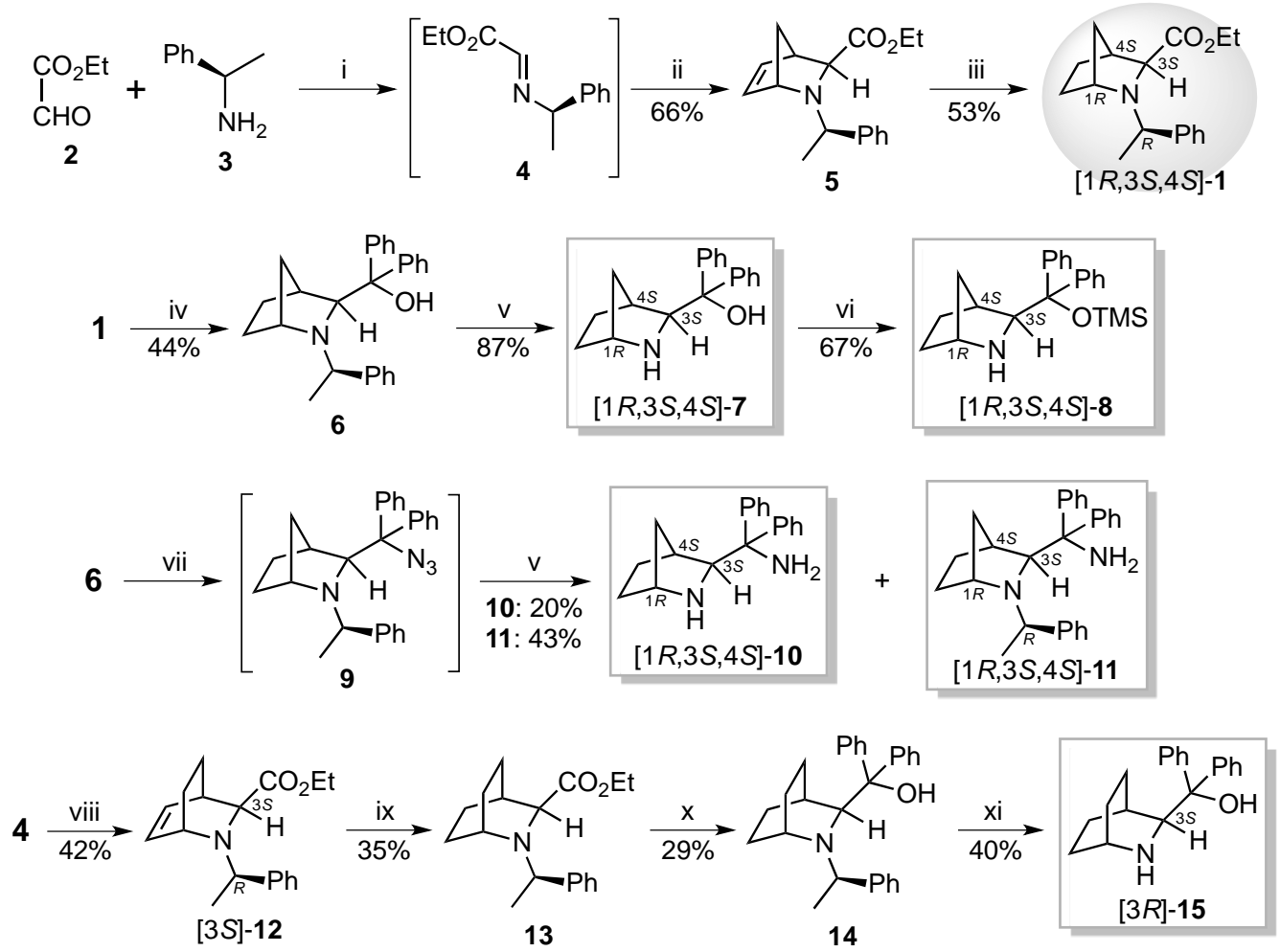

Reagants. i: $\mathrm{MS} 4 \AA \mathrm{CH}_{2} \mathrm{Cl}_{2}, 0^{\circ} \mathrm{C}, 1 \mathrm{~h}$; ii: cyclopentadiene, $\mathrm{CF}_{3} \mathrm{CO}_{2} \mathrm{H}, \mathrm{BF}_{3} \cdot \mathrm{Et}_{2} \mathrm{O},-50{ }^{\circ} \mathrm{C}$ to $\mathrm{rt}, 16 \mathrm{~h} ;$ iii: $\mathrm{H}_{2}, 10 \%$ Pd-C, EtOAc, rt, 24 h; iv: PhMgBr, THF, $0{ }^{\circ} \mathrm{C}$ to rt, 24 h; v: $\mathrm{H}_{2}, 20 \% \mathrm{Pd}(\mathrm{OH})_{2}$, EtOAc, $45^{\circ} \mathrm{C}$, 48 h; vi: TMSOTf, $\mathrm{Et}_{3} \mathrm{~N}, \mathrm{CH}_{2} \mathrm{Cl}_{2},-30{ }^{\circ} \mathrm{C}$ to rt, $24 \mathrm{~h}$; vii: $\mathrm{NaN}_{3}, \mathrm{H}_{2} \mathrm{SO}_{4}$, toluene, rt, $2 \mathrm{~h}$; viii: cyclohexadiene, $\mathrm{CF}_{3} \mathrm{CO}_{2} \mathrm{H}, \mathrm{BF}_{3} \cdot \mathrm{Et}_{2} \mathrm{O}$, $-78^{\circ} \mathrm{C}$ to rt, 16 h; ix: $\mathrm{H}_{2}, 10 \% \mathrm{Pd}-\mathrm{C}$, EtOAc, rt, $12 \mathrm{~h}$; x: PhMgBr, 1,4-dioxane, reflux, $24 \mathrm{~h}$; xi: $\mathrm{H}_{2}, 20 \% \mathrm{Pd}(\mathrm{OH})_{2}$, EtOAc, $45^{\circ} \mathrm{C}, 72 \mathrm{~h}$

Scheme 3. Preparations of cage type organocatalysts 7,8,10,11,15

Initially, we examined the aldol reaction of isatin 16 with cyclohexanone $\mathbf{1 7}$ using the synthesized cage type amine organocatalysts 7, 8, 10, 11 and $15(20 \mathrm{~mol} \%)$ in the presence of trifluoroacetic acid (TFA) (10 mol\%) as a co-catalyst at room temperature for $24 \mathrm{~h}$ (Table 1). All of the catalysts showed asymmetric catalytic activities (7-38\% ee) and the corresponding aldol products, 18 (syn) and 18' (anti), were obtained in low to good chemical yields (10-84\%) and with low to moderate diastereoselectivities (syn:anti $=48: 52-86: 14)$. The absolute configuration and syn:anti stereoselectivity of the aldol products, $\mathbf{1 8}$ and 18', were determined by comparison with the literature data. ${ }^{4 c, g, j, r, u}$ The reaction using catalyst 7 with diphenyl hydroxyl group afforded the product $\mathbf{1 8}$ in good chemical yield and enantioselectivity $(84 \%, 38 \%$ ee, entry 1$)$. 
On the other hand, the use of catalyst $\mathbf{8}$, in which the hydroxyl group was protected by a TMS group, gave the product $\mathbf{1 8}^{\prime}$ in low chemical yield and enantioselectivity $(10 \%, 24 \%$ ee, entry 2$)$. These results indicate that the presence of a free hydroxyl group at the side chain in the catalyst might be necessary to realize satisfactory results. Although catalyst $\mathbf{1 0}$ with a diphenyl amino group as a hydrogen bonding site gave the corresponding product 18' in moderate chemical yield and diastereoselectivity $(46 \%$, syn:anti $=62: 38)$, the enantioselectivity was low $(18 \%$ ee $)$ (entry 3). The use of catalyst $\mathbf{1 1}$ with a primary amino group as an enamine formation site at the side chain afforded product $\mathbf{1 8}^{\prime}$ in low chemical yield and enantioselectivity (12\%, 20\% ee, entry 4). In addition, the catalytic activity of $\mathbf{1 5}$ with a 2-azabicyclo[2.2.2]octane ring system was also examined (entry 5). However, the catalyst $\mathbf{1 5}$ did not show better catalytic activity than that of catalyst 7 having 2-azabicyclo[2.2.1]heptane ring system. Similarly, the simple $\beta$-amino alcohol catalyst 19 was also not effective in this reaction (entry 6). From these results, it was indicated that the use of catalyst $\mathbf{7}$ bearing diphenyl hydroxyl group as the substituent group on the side chain is effective for this reaction to obtain the aldol product in satisfactory chemical yield and stereoselectivity.

\section{Table 1}

Enantioselective aldol reaction of $\mathbf{1 6}$ with 17 using organocatalysts $7,8,10,11,15,19$
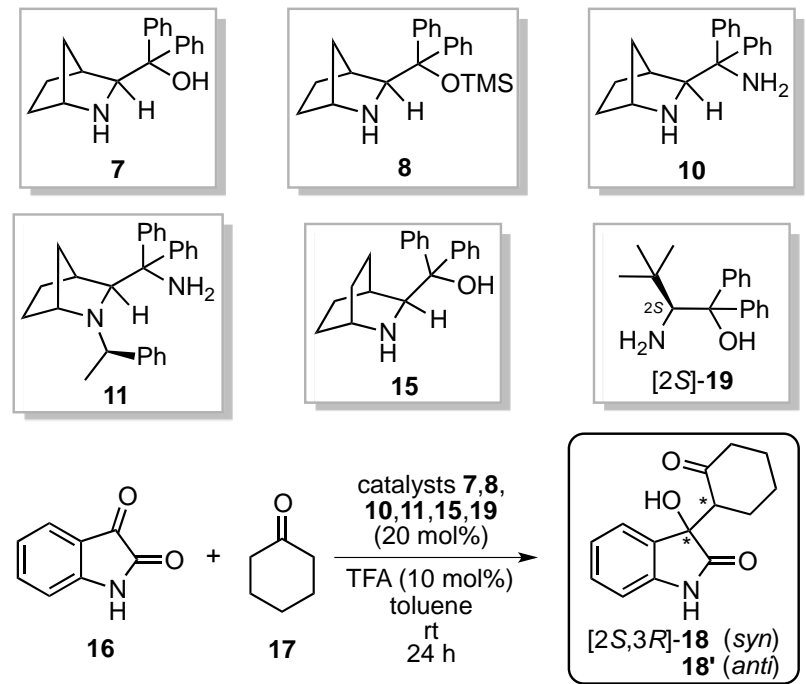

\begin{tabular}{|c|c|c|c|c|c|}
\hline 16 & & & & {$[2 S, 3 R]$} & 18 \\
\hline \multirow{2}{*}{ entry } & \multirow{2}{*}{ cat. } & \multirow{2}{*}{$\begin{array}{l}\text { yield } \\
(\%)^{a} \\
\end{array}$} & \multirow{2}{*}{$\begin{array}{c}\text { syn: } \\
\text { anti } b\end{array}$} & \multicolumn{2}{|c|}{ ee $(\%)^{c}$} \\
\hline & & & & 18 & 18 \\
\hline 1 & 7 & 84 & $40: 60$ & 38 & 30 \\
\hline 2 & 8 & 10 & $54: 46$ & 10 & 24 \\
\hline 3 & 10 & 46 & $62: 38$ & racemic & 18 \\
\hline 4 & 11 & 12 & $86: 14$ & 17 & 20 \\
\hline 5 & 15 & 39 & $44: 56$ & 19 & 33 \\
\hline 6 & 19 & 17 & $48: 52$ & 7 & 22 \\
\hline
\end{tabular}


In order to optimize the reaction conditions using superior 2-azanorbornylmethanol organocatalyst 7, we next examined the effect of the solvent, the molar ratio of catalyst, co-catalyst, the reaction temperature and the reaction time (entries 1-24, Table 2). From the results, it can be seen that the aldol products 18 and 18' were obtained in good chemical yield $(84 \%)$ and with moderate diastereoselectivity $($ syn/anti $=40: 60)$ and enantioselectivity $(38 \%$ ee), when the reaction was carried out in toluene by using $20 \mathrm{~mol} \%$ of catalyst 7 and $10 \mathrm{~mol} \%$ of TFA as co-catalyst at room temperature for $24 \mathrm{~h}$ (Table 2, entry 16).

Table 2

Optimization of the reaction conditions of $\mathbf{1 6}$ with $\mathbf{1 7}$ using organocatalyst 7

\begin{tabular}{|c|c|c|c|c|c|c|c|c|c|}
\hline \multirow{3}{*}{ entry } & \multirow{3}{*}{ solvent } & $6+17$ & \multicolumn{2}{|c|}{$\begin{array}{l}\text { catalyst } 7 \\
\text { co-cat. }(10 \mathrm{~mol} \%) \\
\text { solvent } \\
\text { temp. } \\
\text { time }\end{array}$} & \multicolumn{2}{|c|}{ 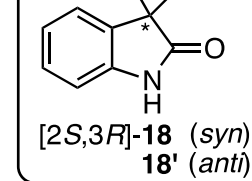 } & \multirow{3}{*}{$\begin{array}{c}\text { syn: } \\
\text { anti } b\end{array}$} & & \\
\hline & & cat. & temp. & time & co-cat. & yield & & \multicolumn{2}{|c|}{ ee $(\%)^{c}$} \\
\hline & & $(\mathrm{mol} \%)$ & $\left({ }^{\circ} \mathrm{C}\right)$ & (h) & & $(\%)^{a}$ & & & 18 \\
\hline 1 & DMF & 20 & rt & 24 & - & 39 & $49: 51$ & 12 & 1 \\
\hline 2 & $\mathrm{MeCN}$ & 20 & rt & 24 & - & 51 & $46: 54$ & 15 & 23 \\
\hline 3 & $\mathrm{CH}_{2} \mathrm{Cl}_{2}$ & 20 & $\mathrm{rt}$ & 24 & - & 56 & $35: 65$ & 32 & 25 \\
\hline 4 & $\mathrm{Et}_{2} \mathrm{O}$ & 20 & $\mathrm{rt}$ & 24 & - & 79 & $39: 61$ & 32 & 32 \\
\hline 5 & THF & 20 & rt & 24 & - & 73 & $40: 60$ & 28 & 26 \\
\hline 6 & 1,4-dioxane & 20 & rt & 24 & - & 44 & $42: 58$ & 28 & 26 \\
\hline 7 & toluene & 20 & $\mathrm{rt}$ & 24 & - & 84 & $37: 63$ & 35 & 32 \\
\hline 8 & benzene & 20 & $\mathrm{rt}$ & 24 & - & 83 & $39: 61$ & 30 & 30 \\
\hline 9 & $\mathrm{MeOH}$ & 20 & rt & 24 & - & 95 & $52: 48$ & 5 & 9 \\
\hline 10 & water & 20 & rt & 24 & - & 84 & $41: 59$ & 20 & 22 \\
\hline 11 & sea water & 20 & rt & 24 & - & 86 & $42: 58$ & 18 & 30 \\
\hline 12 & distilled water & 20 & $\mathrm{rt}$ & 24 & - & 84 & $42: 58$ & 17 & 17 \\
\hline 13 & toluene & 15 & rt & 24 & - & 84 & $37: 63$ & 33 & 31 \\
\hline 14 & toluene & 10 & rt & 24 & - & 74 & $37: 63$ & 33 & 31 \\
\hline 15 & toluene & 5 & rt & 24 & - & 27 & $37: 63$ & 30 & 30 \\
\hline 16 & toluene & 20 & rt & 24 & TFA & 84 & $40: 60$ & 38 & 30 \\
\hline 17 & toluene & 20 & rt & 24 & TCA & 36 & $47: 53$ & 35 & 34 \\
\hline 18 & toluene & 20 & rt & 24 & $\mathrm{TfOH}$ & 84 & $58: 42$ & 19 & 20 \\
\hline 19 & toluene & 20 & $\mathrm{rt}$ & 24 & formic acid & 38 & $43: 57$ & 36 & 35 \\
\hline 20 & toluene & 20 & rt & 24 & benzoic acid & 42 & $39: 61$ & 29 & 32 \\
\hline 21 & toluene & 20 & rt & 24 & acetic acid & 49 & $44: 56$ & 24 & 31 \\
\hline 22 & toluene & 20 & rt & 24 & $p-\mathrm{TsOH}$ & 64 & $49: 51$ & 37 & 33 \\
\hline 23 & toluene & 20 & 0 & 24 & TFA & 82 & $47: 53$ & 36 & 33 \\
\hline 24 & toluene & 20 & $\mathrm{rt}$ & 12 & TFA & 29 & $50: 50$ & 36 & 30 \\
\hline
\end{tabular}

After optimizing the reaction conditions, we investigated the generality of the reaction of isatins 20a-i with different substitution patterns and electronic properties with cyclohexanone $\mathbf{1 7}$ using catalyst 7 under the best reaction conditions (entries 1-9, Table 3). ${ }^{4 c, j, 7}$ As can be seen from 
the results, they all afforded the corresponding aldol products 21a-i (syn) and 21'a-i (anti), although the products were obtained as a mixture of syn/anti diastereomers (syn:anti = 42:58-43:57). The reaction using synthetically useful $N$-Me-isatin $\mathbf{2 0 a}^{5}$ afforded the aldol product 21a in good chemical yield and enantioselectivity $(86 \%, 64 \%$ ee), although it took a long reaction time (entry 1). The use of $N$-benzyl-20b and $N$-allyl-20c isatins also gave the aldol products 21'b and 21c in moderate chemical yields (21'b: 54\%, 21c: 62\%) and enantioselectivities (21'b: $49 \%$ ee, 21c: $47 \%$ ee), respectively, but syn:anti diastereoselectivity was poor (syn:anti $=50: 50$ ) (entries 2, 3). However, the same reaction using $N$-Boc-isatin 20d did not proceed, although the reason for this was not clear (entry 4). Isatin 20e bearing electron donating methyl group on aromatic ring afforded the product 21e in moderate chemical yield and enantioselectivity (32\%, 30\% ee, entry 5). Isatins $\mathbf{2 0 f}-\mathbf{h}$ bearing halogen atoms on the aromatic ring also afforded the corresponding products 21 'f-h, respectively, in good chemical yields and enantioselectivities $(64-79 \%, 35-39 \%$ ee, entries 6-8). The reaction of isatin 20i bearing a strong electron withdrawing $\mathrm{NO}_{2}$ group on the aromatic ring also afforded product $21 \mathbf{i}$ in moderate chemical yield and enantioselectivity (40\%, 44\% ee, entry 9$)$. These results showed the catalytic activity of $\mathbf{7}$ to the aldol reaction of different substituted isatins.

Table 3

Enantioslective aldol reactions of 20a-i with 17 using organocatalyst 7

\begin{tabular}{|c|c|c|c|c|c|c|c|c|c|c|}
\hline \multirow[b]{2}{*}{ entry } & \multicolumn{2}{|c|}{$20 a-i R^{2}$} & + & 17 & $\begin{array}{r}\text { cat } \\
(20 \\
\text { TFA } \\
\text { to }\end{array}$ & $\begin{array}{l}\text { alyst } 7 \\
\text { mol\%) } \\
\begin{array}{l}\text { molo } \\
\text { uene } \\
\text { it } \\
\text { ime }\end{array}\end{array}$ & & $\begin{array}{l}S, 3 R]- \\
R, 3 S]\end{array}$ & $\begin{array}{r}\mathrm{R}^{2} \\
21 \mathrm{c}-\mathbf{i}(s \\
21 \mathbf{a}, \mathbf{b}(s) \\
21 \text { 'a-i }(a\end{array}$ & $\begin{array}{l}\text { syn) } \\
\text { syn) } \\
\text { anti) }\end{array}$ \\
\hline & 20 & $\mathrm{R}^{1}$ & $\mathrm{R}^{2}$ & 21 & $\begin{array}{c}\text { time } \\
(\mathrm{h})\end{array}$ & $\begin{array}{l}\text { yield } \\
(\%)^{a}\end{array}$ & $\begin{array}{l}\text { syn: } \\
\text { anti } b\end{array}$ & 21c-i & $\begin{array}{c}\text { ee }(\%)^{c} \\
21 a, b\end{array}$ & 21 'a-i \\
\hline 1 & $20 a$ & $\mathrm{H}$ & $\mathrm{Me}$ & $21 a$ & 120 & 86 & $43: 57$ & & 64 & 32 \\
\hline 2 & $20 \mathrm{~b}$ & $\mathrm{H}$ & $\mathrm{Bn}$ & $21 b$ & 120 & 54 & $50: 50$ & & 24 & 49 \\
\hline 3 & $20 \mathrm{c}$ & $\mathrm{H}$ & Allyl & $21 \mathrm{c}$ & 120 & 62 & $50: 50$ & 47 & & 25 \\
\hline 4 & $20 \mathrm{~d}$ & $\mathrm{H}$ & Boc & 21d & 120 & - & - & - & & - \\
\hline 5 & $20 \mathrm{e}$ & $\mathrm{Me}$ & $\mathrm{H}$ & $21 e$ & 24 & 32 & $56: 44$ & 30 & & 22 \\
\hline 6 & $20 f$ & $F$ & $\mathrm{H}$ & $21 f$ & 24 & 79 & $42: 58$ & 32 & & 35 \\
\hline 7 & $20 \mathrm{~g}$ & $\mathrm{Cl}$ & $\mathrm{H}$ & $21 \mathrm{~g}$ & 24 & 64 & $45: 55$ & 31 & & 39 \\
\hline 8 & $20 \mathrm{~h}$ & $\mathrm{Br}$ & $\mathrm{H}$ & $21 \mathrm{~h}$ & 24 & 71 & $49: 51$ & 28 & & 35 \\
\hline 9 & $20 \mathrm{i}$ & $\mathrm{NO}_{2}$ & $\mathrm{H}$ & $21 \mathrm{i}$ & 24 & 40 & $52: 48$ & 44 & & 22 \\
\hline
\end{tabular}

Next, we examined the scope of the aldol reaction of isatin $\mathbf{1 6}$ with several acyclic or cyclic ketones 22a-f using catalyst 7 under the same reaction conditions (entries 1-6, Table 4). The 
reaction with acetone 22a afforded the corresponding aldol product 23a with moderate chemical yield and poor enantioselectivity $(43 \%, 13 \%$ ee, entry 1$)$. $^{4 \mathrm{c}, \mathrm{b}, \mathrm{g}, \mathrm{k}, \mathrm{m}, \mathrm{n}, \mathrm{r}, \mathrm{s,u}}$ The use of cyclopentanone 22b gave the aldol product $\mathbf{2 3}$ 'b in good chemical yield (74\%) with moderate enantioselectivities $(43 \%$ ee) and moderate diastereoselectivity (syn:anti $=36: 63)($ entry 2$){ }^{4 c, 7}$ Although bulkier cycloheptanone 22c provided the product 23'c with moderate enantioselectivity ( $46 \%$ ee), the reaction hardly proceeded $(8 \%)$ (entry 3 ). The use of heterocyclic ketones 22d-f also afforded the corresponding products, 23'd,e and 23f, respectively, but the syn:anti stereoselectivity was poor (entries 4-6). The reaction using tetrahydropyran-4-one $\mathbf{2 2 d}$ afforded product $\mathbf{2 3}$ 'd with moderate chemical yield and low enantioselectivity $(37 \%, 14 \%$ ee, entry 4$) .{ }^{4 c}$ Although, tetrahydrothipyran-4-one 22e furnished product $\mathbf{2 3}$ 'e with good chemical yield ( $82 \%)$, the enantioselectivity was low (23\%ee, entry 5$){ }^{4 \mathrm{c}}$ The reaction with piperidin-4-one $22 \mathrm{f}$ led to an increase in both the chemical yield (91\%) and the enantioselectivity ( $37 \%$ ee) (entry 6$).^{4 c}$

\section{Table 4}

Enantioseletive aldol reactions of the $\mathbf{1 6}$ with $\mathbf{2 2 a - f}$ using organocatalyst 7

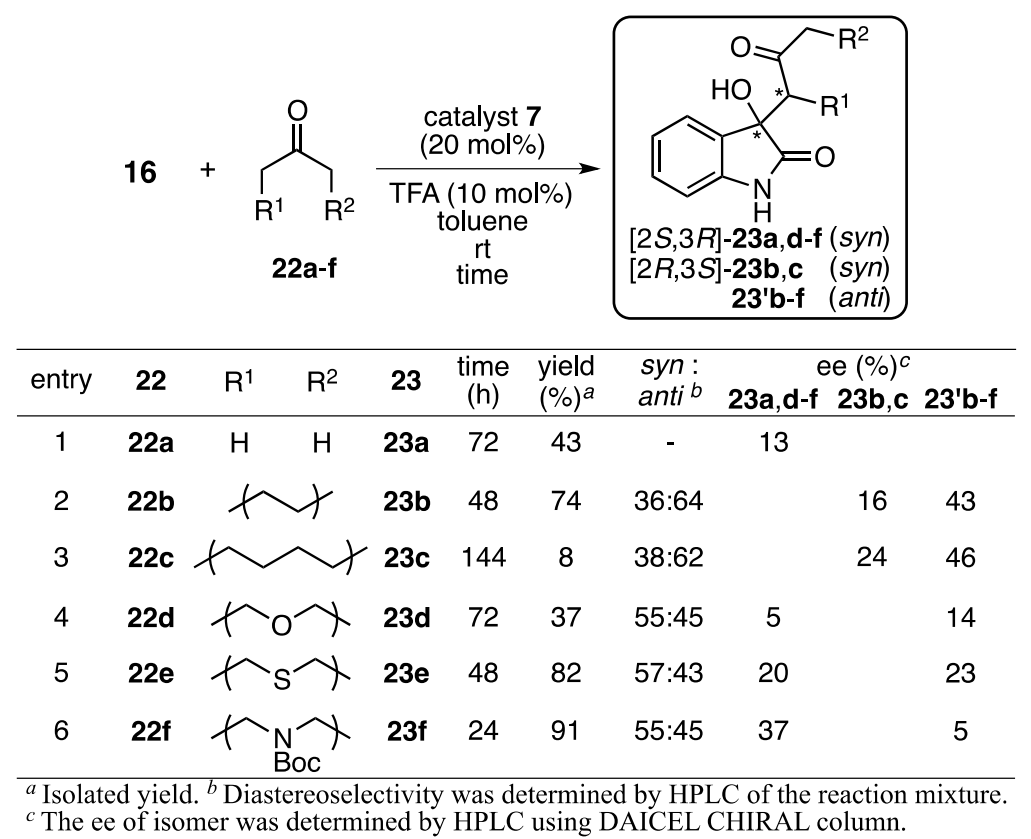

Unfortunately, although satisfactory enantioselectivities and syn:anti diastereoselectivities were not observed in this reaction using a cage type organocatalyst, a model of the enantioselective reaction course was proposed based on the observed enantiopurity $(38 \%$ ee, entry 16, Table 1) of chiral aldol product $(2 S, 3 R)-\mathbf{1 8}$, which was obtained from the reaction of 16 with 17, as follows (Scheme 4). The combination of catalyst 7, cyclohexanone $\mathbf{1 7}$ and TFA 


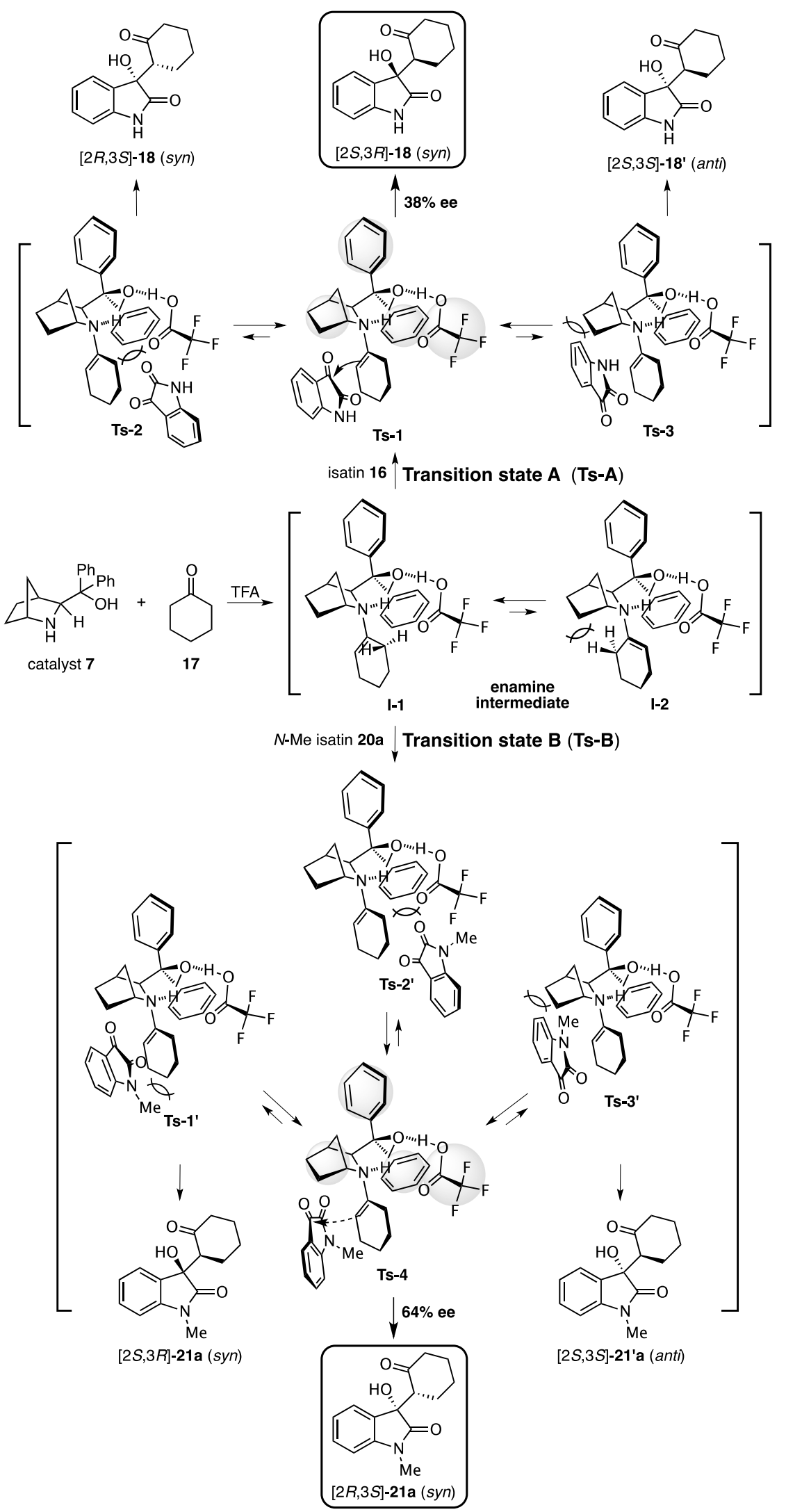

Scheme 4. Plausible reaction course. 
forms an enamine intermediate $\mathbf{I}$. The conformation of intermediate $\mathbf{I}$ is fixed by the hydrogen bonding interaction between the amine nitrogen atom at the enamine part and the hydroxyl hydrogen atom at the side chain, and it might exist as intermediate $\mathbf{I - 1}$, which has less steric interaction between the cage structure and the methylene part in the cyclohexene ring at the enamine part than that of $\mathbf{I - 2}$. The reaction could then proceed through transition state Ts-1 in Ts-A, which has a smaller steric interaction between intermediate I-1 and isatin 16 than Ts-2, which could experience a more severe repulsive interaction between intermediate I-1 and $\mathbf{1 6}$. Furthermore, the syn:anti stereochemistry in the reaction might depend on the steric interaction between 2-azanorbornane ring system in I-1 and 16. Thus, Ts-1 (syn) has less steric interaction between the 2-azanorbornane ring system and 16, rather than through Ts-3 (anti), which has greater steric interaction between I-1 and 16. Furthermore, considering the results that the use of bulkier $N$-methylisatin 20a afforded the product 21a (syn) with the best enantioselectivity (64\% ee, entry 1, Table 3) in all reactions, the reaction could proceed through the Ts-4 in Ts-B, which has less steric interaction between both the cage structure and the methylene parts in the enamine intermediate and isatin 21a, rather than that of Ts-1', Ts-2' and Ts-3'.

\section{Conclusion}

In conclusion, we have reported on the first example of the enantioselective aldol reaction of isatins with acyclic or cyclic ketones using 2-azanorbornane-based amines 7, 8, 10, 11 and 15 as organocatalysts. Among all of these catalysts, 2-azanorbornanemethanol 7 provided the corresponding aldol products in excellent chemical yields (up to 95\%) and with moderate stereoselectivities (up to $64 \%$ ee, syn:anti $=36: 64$ ). Further studies, including catalyst design modifications to improve the stereoselectivity and mechanistic investigations are in progress.

\section{Experimental}

\subsection{General}

All commercial reagents were purchased and used without further purification. All reactions were carried out under argon in flame-dried glassware with magnetic stirring. Thin layer chromatography was performed on silica gel $60 \mathrm{~F}_{254}$, and then detected by using UV light (254 $\mathrm{nm})$ and iodine vapor. Column chromatography was carried out on silica gel $60 \mathrm{~N}(40-100 \mu \mathrm{m})$, and preparative TLC was carried out on silica gel $60 \mathrm{~F}_{254}$. Infrared (IR) spectra were measured with a FT/IR spectrophotometer (JASCO FT/IR-400). Melting points were measured using a 
micro melting point apparatus. NMR spectra were measured using a JEOL JNM-ECA500. ${ }^{1} \mathrm{H}$ NMR $(500 \mathrm{MHz})$ and ${ }^{13} \mathrm{C}$ NMR $(125 \mathrm{MHz})$ spectra were measured in $\mathrm{CDCl}_{3}$ and $\mathrm{DMSO}^{-\mathrm{d}_{6}}$ as solvent and given in $\mathrm{ppm}$ from tetramethylsilane $(0.0 \mathrm{ppm})$ or the residual solvents as a internal standard (DMSO- $\mathrm{d}_{6} ; 2.50 \mathrm{ppm}$ from ${ }^{1} \mathrm{H}$ NMR, $\mathrm{CDCl}_{3} ; 77.16 \mathrm{ppm}$ from ${ }^{13} \mathrm{C} \mathrm{NMR}$ ). Multiplicity of chemical shift are reported as $\mathrm{s}=$ singlet, $\mathrm{d}=$ doublet, $\mathrm{t}=$ triplet, $\mathrm{q}=$ quartet, $\mathrm{dd}=$ doublet of doublets, $\mathrm{m}=$ multiplet and $\mathrm{br}=$ broad and coupling constants $J$ are given in Hz. Diastereo ratio and enantiomeric excess were determined by high performance liquid chromatography (HPLC) with DAICEL CHIRALPAK AD-H, CHIRALPAK AS-H, CHIRALPAK IC and CHIRALCEL $\mathrm{OJ}-\mathrm{H}$.

\section{2. $(1 R, 3 S, 4 S)$-2-Azabicyclo[2.2.1] heptane-3-exo-diphenyl(trimethylsilyoxy)methane 8}

To the solution of $7(0.101 \mathrm{~g}, 0.4 \mathrm{mmol})$ in dry $\mathrm{CH}_{2} \mathrm{Cl}_{2}(6 \mathrm{~mL})$ were added trimethylsiliyl triflate $(0.1 \mathrm{~mL}, 0.48 \mathrm{mmol})$ and $\mathrm{Et}_{3} \mathrm{~N}(0.7 \mathrm{~mL}, 0.48 \mathrm{mmol})$ simultaneously at $-30{ }^{\circ} \mathrm{C}$ for $10 \mathrm{~min}$ under argon. The solution was stirred at room temperature for $24 \mathrm{~h}$ and quenched with $\mathrm{H}_{2} \mathrm{O}$. The resulting mixture was extracted with $\mathrm{CHCl}_{3}(3 \times 10 \mathrm{~mL})$, and the combined organic layers were washed with brine and dried over $\mathrm{Na}_{2} \mathrm{SO}_{4}$. The solvent was then removed under reduced pressure and the residue was purified by flash chromatography on silica gel (EtOAc) to give $\mathbf{8}$ $(0.09 \mathrm{~g}, 67 \%)$ as a white solid; m.p. $180-181{ }^{\circ} \mathrm{C}$ (ether/n-hexane). $[\alpha]_{\mathrm{D}}{ }^{20}=+24.5$ (c 1.06, $\left.\mathrm{CHCl}_{3}\right)$. IR (neat) $\mathrm{cm}^{-1}: 3030,1383,1226 .{ }^{1} \mathrm{H} \mathrm{NMR}\left(\mathrm{CDCl}_{3}, 500 \mathrm{MHz}\right) \delta: 7.41-7.32(\mathrm{~m}, 8 \mathrm{H})$, 7.27-7.26 (m, 2H), $4.26(\mathrm{~s}, 1 \mathrm{H}), 4.03(\mathrm{~s}, 1 \mathrm{H}), 2.61(\mathrm{~s}, 1 \mathrm{H}), 2.16-2.13(\mathrm{~m}, 1 \mathrm{H}), 1.79-1.72(\mathrm{~m}, 3 \mathrm{H})$, $1.21(\mathrm{~d}, J=11.7 \mathrm{~Hz}, 1 \mathrm{H}), 0.98(\mathrm{~d}, J=11.7 \mathrm{~Hz}, 1 \mathrm{H}),-0.11(\mathrm{~s}, 9 \mathrm{H}) .{ }^{13} \mathrm{C} \mathrm{NMR}\left(\mathrm{CDCl}_{3}, 125 \mathrm{MHz}\right)$ $\delta: 141.9,141.5,128.8,128.7,128.4,128.3,81.4,70.4,58.5,39.9,35.2,28.7,25.6,1.71$. Ms $m / z: 351[\mathrm{M}+\mathrm{H}]$. HRMS (EI) calcd for $\left(\mathrm{C}_{22} \mathrm{H}_{29} \mathrm{NOSi}\right): 351.2018$, found: 351.2022 .

\subsection{General procedure for the synthesis of cage type organocatalysts 10 and 11.}

To a solution of $\mathrm{NaN}_{3}(0.456 \mathrm{~g}, 7 \mathrm{mmol})$ in toluene $(14 \mathrm{~mL})$ was added concentrated sulfuric acid $(0.38 \mathrm{~mL}, 7 \mathrm{mmol})$ dropwise for $10 \mathrm{~min}$, after which the mixture was stirred for $15 \mathrm{~min}$ at room temperature. To this mixture, a solution of $7(0.369 \mathrm{~g}, 1 \mathrm{mmol})$ in toluene $(15 \mathrm{~mL})$ was added via syringe at ice-cold temperature and the resulting mixture was stirred vigorously for 2 $\mathrm{h}$ at room temperature. The reaction mixture was quenched with a saturated $\mathrm{NaHCO}_{3}$ solution, and then organic layer was extracted with EtOAc $(3 \times 10 \mathrm{~mL})$. The combined organic extracts were washed with brine and dried over $\mathrm{Na}_{2} \mathrm{SO}_{4}$. The solvent was removed under reduced pressure to give 9. A solution of $9(0.323 \mathrm{~g}, 0.8 \mathrm{mmol})$ and $\mathrm{Pd}(\mathrm{OH})_{2}(0.2 \mathrm{~g})$ in EtOAc $(25 \mathrm{~mL})$ 
was stirred under a hydrogen atmosphere at $45{ }^{\circ} \mathrm{C}$ for $48 \mathrm{~h}$. After removal of the catalyst by filtration, the filtrate was concentrated in vасиo and residue was purified by flash chromatography on silica gel $\left(\mathrm{MeOH}: \mathrm{CHCl}_{3}=1: 7\right)$ to give $\mathbf{1 0}$ and $\mathbf{1 1}$.

\subsection{1. $(1 R, 3 S, 4 S)$-2-Azabicyclo[2.2.1]heptane-3-exo-diphenylmethylamine 10}

White solid; m.p. $148-149{ }^{\circ} \mathrm{C}$ (ether $/ n$-hexane). $[\alpha]_{\mathrm{D}}{ }^{20}=+39.1\left(c 0.23, \mathrm{CHCl}_{3}\right.$ ); IR (neat) $\mathrm{cm}^{-1}: 1596,1473 .{ }^{1} \mathrm{H}$ NMR $\left(\mathrm{CDCl}_{3}, 500 \mathrm{MHz}\right) \delta:$ 7.49-7.42 (m, 4H), 3.97 (s, 1H), $3.45(\mathrm{~s}, 1 \mathrm{H})$, $2.40(\mathrm{~s}, 1 \mathrm{H}), 1.68-1.57(\mathrm{~m}, 3 \mathrm{H}), 1.50(\mathrm{~d}, J=10.6 \mathrm{~Hz}, 1 \mathrm{H}), 1.24(\mathrm{~s}, 1 \mathrm{H}), 1.10$ (d, $J=10.6 \mathrm{~Hz}$, 1H). ${ }^{13} \mathrm{C} \mathrm{NMR}\left(\mathrm{CDCl}_{3}, 125 \mathrm{MHz}\right) \delta: 128.6,128.5,127.1,126.9,126.8,77.4,77.1,68.2,63.0$, 57.1, 38.8, 35.8, 30.8. Ms $m / z: 278$ [M+H]. HRMS (EI) calcd for $\left(\mathrm{C}_{19} \mathrm{H}_{22} \mathrm{~N}_{2}\right): 278.1783$, found: 278.1788 .

\subsection{2. $(1 R, 3 S, 4 S)-2-[(R)-1-P h e n y l e t h y l]-2-a z a b i c y c l o[2.2 .1]$ heptane-3-exo-diphenylmethyl amine 11}

White solid; m.p. $163-164{ }^{\circ} \mathrm{C}$ (ether $/ n$-hexane). $[\alpha]_{\mathrm{D}}^{22}=+90.9\left(c 0.11, \mathrm{CHCl}_{3}\right)$; IR (neat) $\mathrm{cm}^{-1}: 1596,1190 .{ }^{1} \mathrm{H}$ NMR $\left(\mathrm{CDCl}_{3}, 500 \mathrm{MHz}\right) \delta: 7.61-7.58(\mathrm{~m}, 4 \mathrm{H}), 7.31-7.26(\mathrm{~m}, 3 \mathrm{H})$, 7.23-7.14 (m, 7H), 7.04-7.01 (m,1H), 3.77 (s, 1H), 3.05 (s, 1H), 2.93 (q, J = 7.2 Hz, 1H), 2.43 (s, 1H), 1.98-1.92 (m, 1H), 1.68-1.60 (m, 3H), 1.43-1.34 (m, 1H), 1.18 (d, $J=7,2 \mathrm{~Hz}, 3 \mathrm{H}), 0.85$ (d, $J=9.2 \mathrm{~Hz}, 1 \mathrm{H}) .{ }^{13} \mathrm{C} \mathrm{NMR}\left(\mathrm{CDCl}_{3}, 125 \mathrm{MHz}\right) \delta: 128.2,128.1,128.0,127.9,127.8,126.4,126.3$, 126.2, 126.1, 125.9, 69.9, 63.6, 55.7, 55.2, 42.1, 39.1, 32.4, 30.8, 29.7, $13.8 \mathrm{Ms} m / z: 382[\mathrm{M}+\mathrm{H}]$. HRMS (EI) calcd for $\left(\mathrm{C}_{27} \mathrm{H}_{30} \mathrm{~N}_{2}\right): 382.2409$, found: 382.2413 .

\subsection{General procedure for the enantioselective aldol reaction of isatins with ketones.}

To a stirred solution of catalyst $7(0.02 \mathrm{mmol})$ in dry toluene $(0.2 \mathrm{~mL})$ were added ketone $(2$ $\mathrm{mmol})$, TFA $(0.01 \mathrm{mmol})$ and isatin $(0.1 \mathrm{mmol})$ simultaneously at room temperature. The reaction mixture was stirred at this temperature for the appropriate time and then quenched with $\mathrm{H}_{2} \mathrm{O}$. Toluene was then removed under reduced pressure, and the residue was extracted with EtOAc $(3 \times 2 \mathrm{~mL})$. The combined organic layers were dried over $\mathrm{Na}_{2} \mathrm{SO}_{4}$ and the solvent was evaporated under reduced pressure. The resulting residue was purified by flash chromatography on silica gel $(n$-hexane:EtOAc $=2: 3)$ to give the corresponding aldol products.

\section{References}


1. (a) V. M. R. Chandra, A. Luliana, R. Magnus, Chem. Rev. 2014, 114, 2390-2431; (b) M.

Albert, R. Rois, Chem. Rev. 2011, 111, 4703-4832; (c) H. Pellissier, Recent Developments in Asymmetric Organocatalysis; RSC: Cambridge, U.K., 2010.

2. (a) J. Kumagai, T. Otsuki, U. V. Subba Reddy, Y. Kohari, C. Seki, K. Uwai, Y. Okuyama, E. Kwon, M. Tokiwa, M. Takeshita, H. Nakano, Tetrahedron: Asymmetry 2015, 26, 1423-1439;

(b) T. Otsuki, J. Kumagai, Y. Kohari, Y, Okuyama, E. Kwon, C. Seki, K. Uwai, Y, Mawatari, N. Kobayashi, T. Iwasa, M. Tokiwa, M. Takeshita, A. Maeda, A. Hashimoto, K. Turuga, H. Nakano, Eur. J. Org. Chem., 2015, 7292-7300; (c) Y. Kohari, Y. Okuyama, E. Kwon, T. Furuyama, N. Kobayashi, T Otuki, J. Kumagai, C. Seki, K. Uwai, G. Dai, T. Iwasa, H. Nakano, J. Org. Chem. 2014, 79, 9500-9511; (d) C. Suttibut, Y. Kohari, K. Igarashi, H. Nakano, M. Hirama, C. Seki, H. Matsuyama, K. Uwai, N. Takano, Y. Okuyama, K. Osone, M. Takeshita, E. Kwon, Tetrahedron Lett. 2011, 52, 4745-4748; (e) H. Nakano, K. Osone, M. Takeshita, E. Kwon, C. Seki, H. Matsuyama, N. Takao, Y. Kohari, Chem. Commun. 2010, 46, 4827-4829.

3. (a) E. Wojaczyńska, J. Wojaczyński, K. Kleniewska, M. Dorsz, T. K. Olszewski, Org.

Biomol. Chem. 2015, 13, 6116-6148; (b) J. Lu, Y. Xu, F. Liu, T. Loh, Tetrahedron Lett. 2008, 49, 6007-6008; (c) J. Lu, Y. Xu, F. Liu, T. Loh, Tetrahedron Lett. 2008, 49, 5389-5392; (d) Y. Okuyama, H. Nakano, H. Hongo, Tetrahedron: Asymmetry 2000, 11, 1193-1198; (e) D. Guijarro, P. Pinho, P. G. Andersson, J. Org. Chem. 1998, 63, 2530-2535; (f) P. Pinho, D. Guijarro, P. G. Andersson, Tetrahedron 1998, 54, 7897-7906; (g) H. Nakano, K. Iwasa, H. Hongo, Heterocycles 1997, 46, 267-274; (h) H. Nakano, N. Kumagai, H. Matsuzaki, C. Kabuto, Tetrahedron: Asymmetry 1997, 8, 1391-1401; (i) H. Nakano, N. Kumagai, C. Kabuto, H. Matsuzaki, H. Hongo, Tetrahedron: Asymmetry 1995, 6, 1233-1236.

4. (a) G. M. Ziarani, R. Moradi, N. Lashgai, Tetrahedron: Asymmetry 2015, 26, 517-541;

(b) Y. Tanimura, K. Yasunaga, K. Ishimaru, Tetrahedron: Asymmetry 2014, 70, 2816-2821;

(c) H. Zhao, W. Meng, Z. Yang, T. Tian, Z. Sheng, H. Li, X. Song, Y. Zhang, S. Yang, B. Li, Chin. J. Chem., 2014, 32, 417-428; (d) S. Abbaraju, J. C. G. Zhao, Adv. Synth. Catal. 2014, 356, 237-241; (e) Y. Lu, Y. Ma, S. Yang, M. Ma, H. Chu, C. Song, Tetrahedron: Asymmetry 2013, 24, 1082-1088; (f) C. W. Suh, C. W. Chang, K. W. Chio, Y. J. Lim, D. Y. Kim, Tetrahedron Lett. 2013, 54, 3651-3654; (g) Y. Tnimura, Y. Yasunaga, K. Isimaru, Eur. J. Org. Chem., 2013, 29, 6535-6539; (h) A. S. Saiyed, A. V. Bedekar, Tetrahedron: Asymmetry 2013, 24, 1035-1041; (i) B. Zhu, W. Zhang, R. Lee, Z. Han, W. Yang, D. Tan, K. W. Huang, Z. Jiang, Angew. Chem. Int. Ed. 2013, 52, 6666-6670; (j) A. Kumer, S.S. Chimni, Tetrahedron 
2013, 69, 5197-5204; (k) Q. Guo, J. C. G. Zhao, Tetrahedron Lett. 2012, 53, 1768-1771; (1) Y. Liu, P. Gao, J. Wang, Q. Sun, Z. Ge, R. Li, Synlett, 2012, 23, 1031-1034; (m) G. G. Liu, H. Zhao, Y. B. Lan, B. Wu, X. F. Huang, J. Chen, J. C. Tao, Tetrahedron 2012, 68, 3843-3850; (n) C. Shen, F. Shen, H. Xia, P. Zhang, X. Chen, Tetrahedron: Asymmetry 2011, 22, 708-712; (o) S. Allu, N. Molleti, R. Panem, V. K. Singh, Tetrahedron Lett. 2011, 52, 4080-4083; (p) M. Kinsella, P. G. Duggan, C. M. Lennon, Tetrahedron: Asymmetry 2011, 22, 1432-1433; (q) M. Raj, N. Veerasamy, V. K. Singh, Tetrahedron Lett. 2010, 51, 2157-2159; (r) G. Angelici, R. J. Corrêa, S. J. Garden, C. Tomasini, Tetrahedron Lett. 2009, 50, 814-817; (s) R. J. Corrêa, S. J. Garden, G. Angelici, C. Tomasini, Eur. J. Org. Chem. 2008, 736-744; (t) S. Nakamura, N. Hara, H. Nakashima, K. Kubo, N. Shibata, T. Toru, Chem. Eur. J. 2008, 14, 8079-8081; (u) A. V. Malkov, M. A. Kabeshov, M. Bella, O. Kysilka, D. A. Malyshev, K. Pliháčková, P. Kočovský, Org. Lett. 2007, 9, 5473-5476; (v) G. Luppi, P. G. Cozzi, M. Monari, B. Kaptein, Q. B. Broxterman, C. Tomasini, J. Org. Chem. 2005, 70, 7418-7421.

5. (a) J. Kaur, S. S. Chimni, S. Mahajan, A. Kumar, RSC Adv. 2015, 5, 52481-52496; (b) S. P. Parvathaneni, R. Pamanji, V. R. Janapala, S. K. Uppalapati, S. Balasubramanian, M. R. Mandapati, J. Med. Chem. 2014, 84, 155-159; (c) T. Yan, X. Wang, H. Sun, J. Liu, Y. Xie, Molecules, 2013, 18, 14505-14518; (d) A. Kumar, S.S.Chimni, RSC Adv., 2012, 2, 9748-9762; (e) G. S. Singh, Z. Y. Desta, Chem. Rev. 2012, 112, 6104-6155; (f) C. Sultan, C. Mikhail, L. Shifeng, S. Jianyu, R. Vandna, C. Ray, Y. Wendy, K. Rainbow, F. Jianmin, C. A. Jay, Bioorg. Med. Chem. 2011, 21, 3676-3681; (g) S. Peddibhotla, Curr. Bioact. Compd., 2009, 5, 20-38; (h) T. Tokunaga, E. W. Huma, J. Nagamine, T. Kawamura, M. Taiji, R. Nagata, Bioorg. Med. Chem. Lett. 2005, 15, 1789-1792; (i) A, Fréchard, N. Fabre, C. Péan, S. Montaut, M. T. Fauvel, P. Rollin, I. Fourasté, Tetrahedron Lett. 2001, 42, 9015-9017; (j) J. Kohno, Y. Koguchi, M. Nishio, K. Nakao, M. Kuroda, R. Shimizu, T. Ohnuki, S. Komatsubara, J. Org. Chem. 2000, 65, 990-995; (k) J. I. Jimenez, R. E. Moore, G. M. L. Patterson, J. Nat. Prod. 1999, 62, 596-572; (1) Y. Kamano, H. Zhang, Y. Ichihara, H. Kizu, K. Komiyama, G. R. Pettit, Tetrahedron Lett. 1995, 36, 2783-2784.

6. (a) H. N. Roy, A. Pitchaiah, M. Kim, I. T. Hwang, K. Lee, RSC Adv. 2013, 3, 3526-3530;

(e) Y. Sakuta, Y. Kohari, N. D. M. R. Hutabarat, K. Uwai, E. Kwon, Y. Okuyama, C. Seki, H. Matsuyama, N. Takano, M. Tokiwa, M. Takeshita, H. Nakano, Heterocycles 2012, 86, 1379-1389; (b) N. Hashimoto, H. Yasuda, M. Hayashi, Y. Tanabe, Org. Process Res. Dev., 2005, 9, 105-109; (c) V. I. Tararov, R. Kadyrov, Z. Kadyrova, N. Dubrovina, A. Börner, Tetrahedron: Asymmetry 2002, 13, 25-28; (d) H. Abraham, L. Sterlla, Tetrahedron 1992, 48, 
9707-9718.

7. (a) Z. Q. Liu, Z. W. Xiang, Z. Shen, Q. Wu, X. F. Lin, Biochimie 2014, 101, 156-160; (b) Z.Mao, X. Zhu, A. Lin, W. Li, Y. Shi, H. Mao, C. Zhu, Y. Cheng, Adv. Synth. Catal. 2013, 355, 2029-2036. 